\title{
O USO DE REDES SOCIAIS COMO ESTRATÉGIA DE MARKETING EM UNIDADES DE INFORMAÇÃO: estudo de caso da Biblioteca Pública Estadual Graciliano Ramos
}

\author{
Ronaldo Ferreira de Araujo \\ Doutor em Ciência da Informação pela \\ Universidade Federal de Minas Gerais. \\ Professor Adjunto do Curso de \\ Biblioteconomia da Universidade \\ Federal de Alagoas. \\ E-mail: ronaldfa@gmail.com \\ Janiele Oliveira Araújo \\ Bacharel em Biblioteconomia pela \\ Universidade Federal de Alagoas. \\ E-mail: janieleoliveiraa@hotmail.com
}

\section{RESUMO}

Discorre sobre o marketing em unidades de informação com atenção especial ao marketing digital e as métricas de mídias sociais. Verifica o uso de mídias sociais como estratégia de marketing em unidades de informação por meio de um estudo de caso do uso e atuação da Biblioteca Pública Estadual Graciliano Ramos (PBEGR) no Facebook. Analisa o desempenho da página expresso nos indicadores de audiência, engajamento, influência e conversão utilizados para mensurar estratégias do marketing digital. Os resultados indicam o quantitativo de 1728 curtidas na página da biblioteca com predominância de publicações sobre eventos organizados pela BPEGR (48\%). 0 desempenho das postagens indica um valor total de interações com usuários no período analisado de 713 curtidas, 263 compartilhamentos e apenas 16 comentários. Os dados apontam a visibilidade percebida e o grau de autoridade da biblioteca perante os usuários tendo em vista o conteúdo publicado, considerando se houve alcance dos resultados dessas estratégias. Considera-se que as mídias sociais podem sim mobilizar os cidadãos a buscarem a biblioteca pública como uma instituição promotora de conhecimento, lazer e troca social, fazendo com que a biblioteca pública cumpra seu papel enquanto unidade de informação e que para tanto a biblioteca precisa traçar estratégias mais claras de sua utilização e avaliação.

Palavras-chave: Mídias sociais. Marketing. Marketing digital. Social Media Marketing. Biblioteca Pública.

SOCIAL MEDIA AS A MARKETING STRATEGY IN INFORMATION UNITS: case study of the Graciliano Ramos Public Library

\section{ABSTRACT}

Discusses marketing in information units with special attention to digital marketing and social media metrics. It verifies the use of social network sites as a marketing strategy in information units through a case study of the use and performance of the Graciliano Ramos Public 
Library (GRPL) on Facebook. It analyzes the performance of the fanpage expressed in the audience, engagement, influence and conversion indicators used to measure digital marketing strategies. The results indicate the quantitative of 1728 likes on the library fanpage with predominance of publications on events organized by GRPL (48\%). The performance of the posts indicates a total value of interactions with 713 likes, 263 shares and only 16 comments. The data point out the perceived visibility and the degree of authority of the library towards the users in view of the published content, considering the achievement of the results of these strategies. It is considered that social media can mobilize citizens to seek the public library as an institution that promotes knowledge, leisure and social exchange, making the public library play its role as a unit of information and that the library needs to draw clearer use and evaluation strategies.

Keywords: Social networks sites. Digital marketing. Social Media Marketing. Public Library.

\section{INTRODUÇÃO}

A biblioteca exerce um papel fundamental para o desenvolvimento de uma sociedade, pois dispõe de recursos informacionais capazes de instruir o indivíduo fazendo-o desenvolver senso crítico e o torná-lo consciente de seus direitos e deveres.

No manifesto da IFLA/UNESCO (1994) 1 sobre Bibliotecas Públicas, primordialmente é destacado que a liberdade, a prosperidade e o desenvolvimento da sociedade e dos indivíduos são valores humanos fundamentais. E que só serão alcançados quando os cidadãos estiverem na posse da informação que lhes permita exercer os seus direitos democráticos. Dessa forma, o desenvolvimento de uma sociedade depende de vários fatores para uma educação satisfatória, o acesso livre e sem limites ao conhecimento, ao pensamento, à cultura e à informação.

Desde o surgimento e popularização da internet, a comunicação mediada por computador, com destaque para as plataformas de mídias sociais que promovem a formação de redes sociais, a sociedade tem vivenciado constantes mudanças no âmbito da democratização do acesso e compartilhamento de conteúdos. Podemos identificar nesses mecanismos um grande potencial de disseminação e promoção de unidades de

\footnotetext{
${ }^{1}$ International Federation of Library Associations/United Nations Educational Scientific and Cultural Organization.
} 
informação, como as bibliotecas, sobretudo se explorados de forma aliada ao marketing e atenta às particularidades do ambiente digital.

Nesse contexto, ressaltando os desafios enfrentados pelas bibliotecas públicas no desempenho de seu papel no âmbito de uma da sociedade da informação (ARRUDA, 2013) e reconhecendo uso de mídias sociais como importante variável na construção de um novo panorama para as bibliotecas no cenário atual (PRADO; CORREA, 2016), o presente artigo trabalha como problema de pesquisa o seguinte questionamento: como as mídias sociais na internet aliadas ao marketing, podem ser utilizadas na disseminação de informações de modo que a biblioteca também consiga ampliar sua visibilidade? Salientamos neste ponto, a intenção de expor as mudanças das unidades de informações em relação ao uso de ferramentas digitais para atrair novos usuários além de demostrar como o Bibliotecário pode ter uma atuação diferenciada ao utilizar recursos da web $2.0^{2}$ para disseminar a informação e como as mídias sociais podem ser utilizadas como aliadas na aplicação do marketing digital, auxiliando as bibliotecas a tornarem-se mais próximas dos seus usuários.

\section{MARKETING DIGITAL EM UNIDADES DE INFORMAÇÕES}

O Marketing desde sua criação esteve atrelado a atividade mercadológica, uma vez que era visto como um conjunto de atividades humanas que tinha por objetivo facilitar e consumar as relações de troca e o fluxo de mercadorias (KOTLER, 1978). Na medida que as relações sociais e econômicas foram ganhando novas características ao longo da história, o conceito de marketing acompanhou estas modificações e passou por fases, denominadas na literatura da área de "eras" e que correspondem ao período iniciado em meados de 1900 e percorre até os dias atuais.

A primeira era caracterizada com a produção como atividade principal, a segunda denominada como era das vendas, onde tudo era projetado em técnicas agressivas de vendas a fim de acabar com os estoques da produção visando o lucro das empresas e por fim a terceira que teve como ponto principal o cuidado em saber do cliente sua opinião e

\footnotetext{
2"Pode ser considerada uma nova concepção, pois passa agora a ser descentralizada e na qual o sujeito torna-se um ser ativo e participante sobre criação, seleção e troca de conteúdo postado em um determinado site por meio de plataformas abertas" (BLATTMANN; SILVA 2007, p.198)
} 
satisfação, a fim de oferecer produtos desenvolvidos estrategicamente com base em suas necessidades.

Atualmente o marketing vem sendo aplicado nas mais diversas áreas de forma bem abrangente, inclusive em organizações que não visam lucro como é o caso das unidades de informação como bibliotecas, museus, centros de documentação, etc. Não se trata apenas de ser possível, mas é na verdade "aconselhado a utilização do marketing em organizações sem fins lucrativos", desde que se tenha entendido a finalidade do marketing (AMARAL, 2007, p. 124). Segundo Kotler (1978, p. 24) “[...] a razão básica de uma organização que não visa a lucro interessa-se pelos princípios formais do marketing é que eles permitem que a organização se torne mais eficaz na obtenção dos seus objetivos". Adotar estratégias de marketing a biblioteca precisa ser vista como um negócio, pois precisa tanto manter, como atrair novos usuários em contrapartida promover a visibilidade do acervo e demais serviços oferecidos, a fim de que a mesma consiga alcançar seus objetivos. Dessa forma, Batista (1988 apud AMARAL, 1998, p.96) "defende a estratégia de marketing para derrubar barreiras entre biblioteca e usuários".

De modo similar Ottoni (1995, p. 1) aponta que o marketing em unidades de informação pode ser entendido como uma filosofia de gestão administrativa na qual "todos os esforços convergem em promover, com a máxima eficiência possível, a satisfação de quem precisa e de quem utiliza os produtos e serviços de informação. É o ato de intercâmbio de bens e satisfação de necessidades". Assim é necessário traçar um planejamento estratégico aliado ao marketing, a fim de conhecer a situação da instituição para estipular metas e consequentemente alcançar os objetivos da mesma em um constante cenário de mudanças.

O advento da internet e evolução da web têm trazido inúmeras implicações para os processos infocomunicacionais sobretudo a sociabilização através das ferramentas mediadas pelo computador, permitindo o acesso e a troca de informação de forma prática e dinâmica. Amaral $(1999,2000)$ denomina esse ambiente eletrônico ou digital de ciberespaço como sendo o ambiente mais propício e atrativo para desenvolver atividades relacionadas ao marketing, nas mais diferentes organizações. 0 marketing digital, trabalha com a mesma essência mercadológica do marketing tradicional tendo como diferença a maneira como as informações são compartilhadas, utilizando recursos da internet para promover produtos, serviços ou instituições por meio de ferramentas digitais como websites, blogs, mídias sociais, entre outras. 
A proliferação de tecnologias e plataformas digitais "oferece um cenário fértil para as mais diversificadas ações de marketing", inclusive para o Social Media Marketing (SMM), conhecido popularmente como o marketing em redes sociais na internet, compreendido como mecanismo de divulgação de website/produto/marca e utilizando como instrumento para atrair um público-alvo cada vez mais presente nas redes e mídias sociais, de forma que envolva um ou mais estratégias para alcançar os objetivos do marketing (GABRIEL, 2010, 105).

Assim, pensar sobre o uso das mídias sociais no âmbito das bibliotecas é refletir como estas, enquanto unidades de informação, podem atuar no dinamismo dos ambientes digitais, e explorar o melhor que tais ambientes têm a oferecer na promoção de seus produtos e serviços, fazendo uso do SMM como estratégia, a fim de não apenas ganhar visibilidade perante os seus usuários reais e potenciais, mas engajá-los em suas campanhas e estratégias.

Araújo (2015) afirma que as instituições que desejarem empregar o marketing digital precisarão se dedicar a algumas questões essenciais como: construir e manter uma presença online e oferecer um conteúdo adequado. A “[...] presença online é o marco inicial de ingresso aos interessados em atingir um público maior e cada vez mais conectado no ambiente da web" (ARAÚJO, 2015, p. 73). Tal presença traz uma certa visibilidade por si só, mas não se sustenta por muito tempo se não for disponibilizado conteúdo periódico e ao mesmo tempo que seja de interesse do seu público. Assim, as mídias sociais se tornaram facilitadoras para a aplicação do marketing digital para promover a promoção das mais variadas instituições assim como as das bibliotecas.

Promoção é uma atividade de marketing referente à comunicação com o
propósito de fazer conhecer e efetivar o uso ou adoção de um produto,
ideia, comportamento ou serviço. Os objetivos da promoção são: (a)
tornar a organização e seus produtos conhecidos pelos usuários
potenciais; (b) tornar o ambiente da organização e seus serviços mais
atraentes para os usuários potenciais; (c) mostrar aos usuários reais
como usar os produtos e serviços; (d) evidenciar os benefícios dos
produtos e serviços oferecidos; (e) manter os usuários reais,
constantemente, bem informados sobre a atuação da organização, seus
produtos e serviços (AMARAL, 2008, p. 34).

Neste contexto de promover a biblioteca com o uso das mídias sociais, todo seu conteúdo publicado e ações podem ser avaliados por meio de indicadores de valores que podem ser percebidos nas funcionalidades de interações disponíveis nesses ambientes 
que ajudam a avaliar se o conteúdo divulgado está apresentando resultados por meio da mensuração, ou seja, a análise do capital social ${ }^{3}$ gerado. De tal modo, saber se o uso das mídias sociais como estratégia de marketing, está sendo eficaz.

Conforme Gabriel (2010, p. 333): “a mensuração é essencial em qualquer ação de marketing em redes sociais. Pois são as análises das mensurações que confirmam a eficiência das diversas estratégias ou balizam os ajustes que devem ser feitos para melhorar". No SMM, Macedo (2014) explica que as métricas mais utilizadas para mensuração são feitas com base nos indicadores de valores construídos na rede como os propostos por Recuero (2009) como: visibilidade sendo a presença na rede, reputação como a percepção do outro em relação a alguém na rede, popularidade interpretada como valor ou posição que se ocupa dentro de determinada rede e a autoridade refere-se ao poder de influência, todos esses indicadores indicam os tipos de capital social gerado.

Recuero (2009) ressalta ainda que os tipos de capital mais percebidos são: o relacional que consiste na soma das relações, laços e trocas que conectam os indivíduos de uma determinada rede; e o cognitivo que é a soma do conhecimento e das informações colocadas em comum por um determinado grupo. Vale lembrar que existe uma grande variação por meio dos autores quanto as nomenclaturas das métricas, para avaliar cada estratégia de marketing ou mídia social. Ademais no Quadro 1 Macedo (2014) descreve esses grupos que fundamentam os mesmos indicadores de forma geral.

Quadro 1 - Grupos das métricas

\begin{tabular}{|l|l|}
\hline Métricas & \multicolumn{1}{c|}{ Descrição } \\
\hline Audiência & $\begin{array}{l}\text { São métricas relacionadas à exposição do conteúdo, tamanho do público, volume e } \\
\text { frequência. }\end{array}$ \\
\hline Engajamento & $\begin{array}{l}\text { As métricas de engajamento buscam avaliar o quanto a audiência está envolvida, } \\
\text { interagindo, colaborando e participando nas plataformas. }\end{array}$ \\
\hline Influência & $\begin{array}{l}\text { São métricas ligadas a relevância e influência da marca ou empresa nas plataformas que } \\
\text { mapeia quem são os demais influenciadores no nicho do mercado. }\end{array}$ \\
\hline Conversão & $\begin{array}{l}\text { São as métricas relacionadas a conquista, resultados obtidos e eventos relevantes. } \\
\text { Geralmente são quantitativos, baseados em metas. }\end{array}$ \\
\hline
\end{tabular}

Fonte: Adaptado de Macedo, 2014, p. 31.

De acordo com Macedo (2014) as métricas de audiência são as que avaliam tanto a audiência da mídia social quanto o conteúdo divulgado, como por exemplo: números de

\footnotetext{
${ }^{3}$ Segundo Recuero (2009), capital social refere-se a um valor construído a partir das interações e relações, somado ao conteúdo das mensagens trocadas entre os atores nas redes sociais na internet, dos quais a autora classifica por meio de indicadores de valores.
} 
seguidores ou fãs, tweets, frequência de visitas, frequência de publicações ou postagens, visualizações de página entre outros, ou seja, essa métrica está diretamente ligada a visibilidade. De tal forma também é possível avaliar as métricas de engajamento, ou seja, o grau de interação os comentários, compartilhamentos, likes, menções, recomendações, retweets, tempo de visitação, etc.

As métricas de influência servem para mensurar o quanto o canal, pessoas ou postagens tem de influência entre os demais. Inclusive podem ser vistas como a reputação, impacto, conexões, credibilidade que autor tem na rede enquanto influenciador, bem como a quem influencia a compartilhar seus conteúdos. E a métrica de conversão, por sua vez, é vista como um medidor das conquistas finais, ou seja, o resultado alcançado das ações, seja ela o alcance das vendas, repetição de compras, downloads, visualização de vídeos, assim como também se analisa o comportamento do cliente ou usuários, ou se está indo ao encontro de eventos propostos, desde que as metas sejam estabelecidas (MACEDO, 2014).

Ao entender que tais indicadores precisam ser acompanhados torna-se de suma importância a elaboração de um plano de marketing que os considere, levando em consideração a real situação da instituição, seus objetivos, assim como também o estabelecimento das estratégias que serão utilizadas para que as metas sejam alcançadas. O uso das métricas são imprescindíveis para mensuração, pois indicam a eficácia do uso do marketing, de tal forma apresentada como um medidor capaz de avaliar o impacto que a organização tem perante os usuários frente ao uso das mídias sociais, auxiliando os gestores na tomada de decisão, onde se pode melhorar quanto ao conteúdo a ser publicado, contribuindo assim para o alcance de uma maior visibilidade e sucesso da organização.

\section{MATERIAL E MÉTODO}

A presente pesquisa de caráter exploratório e cunho descritivo verifica o uso de mídias sociais como estratégia de marketing em unidades de informação com o enfoque na Biblioteca Pública Estadual Graciliano Ramos (PBEGR). Por meio de um estudo de caso procede a análise de conteúdo das postagens da página oficial da PBEGR no Facebook e das interações que a página recebe. 
O prédio da PBEGR está localizado na cidade de Maceió, na Praça Dom Pedro II, é conhecido como o antigo Palacete "Barão de Jaraguá", o qual foi construído entre anos 1844 e 1849 pelo célebre Antônio Mendonça, para ser a sua residência, só sendo intitulado como Biblioteca, em 01 de abril de 1985 por meio do Decreto no 6219 (SANT'ANA, 2014). Apenas em 18 de novembro de 2013 que a biblioteca, por meio do Decreto no 29.175 de 15 de novembro de 2013, passou a ser chamada de "Biblioteca Pública Estadual Graciliano Ramos", em homenagem ao ilustre e renomado escritor Alagoano Graciliano Ramos.

A PBEGR conta com uma estrutura de: recepção; autoatendimento; almoxarifado; sala de conservação e preservação; salas de leitura; bebeteca e leitura infantil; terminal multimídia; secretaria e direção; telecentro/multimeios; auditório; Memorial Graciliano Ramos; e Fonteca (SANTOS, 2015; 2016). O acervo bibliográfico é composto de aproximadamente 75 mil itens, dentre estes, livros da literatura alagoana, obras raras, acervo em braile, acervo infanto-juvenil e outros de áreas gerais do conhecimento e ainda, mais de 20 mil (vinte mil) para serem avaliados, higienizados, tratados tecnicamente e disponibilizados para consulta (SANTOS, 2015).

A BPEGR oferece os seguintes serviços a fim de atingir seus objetivos enquanto unidade de informação: atendimento ao público em geral; Biblio Tour- Passeio turístico, histórico e cultural dentro da Biblioteca; hora do conto - incentivo à leitura desde crianças; lançamentos de livros; cinemateca - exibição de curtas e longas metragens; inclusão digital - capacitação de informática básica para inserção de jovens da periferia no mercado de trabalho; recital de poesias alagoanas- incentivo ao conhecimento dos escritores existentes em Alagoas; Cordel \& Prosa- promoção da literatura de cordel e sua importância para a formação histórica do Nordeste; Coco, Memória e Cordel - repasse da sabedoria popular da literatura de cordel para a nova geração; comemorações de datas festivas; exposições diversas (SANTOS, 2016).

O último relatório anual de atividades da gestão atual (SANTOS, 2016) registra os membros da equipe (uma bibliotecária, na qualidade de Diretora; cinco estagiários estudantes de Biblioteconomia; nove funcionários efetivos; seis funcionários terceirizado, destes uma recepcionista e cinco auxiliares de serviços gerais) e os canais de comunicação com a biblioteca, sendo um e-mail institucional ${ }^{4}$ e uma página no Facebook $^{5}$, não havendo

\footnotetext{
4 bpe.alagoas@gmail.com

${ }^{5}$ www.facebook.com/BPEGracilianoRamos
} 
para esta última, nenhuma menção quanto ao planejamento, política ou diretrizes de seu uso na biblioteca.

Para analisar a atuação da BPEGR nessa mídia a coleta foi realizada por meio de consulta manual acessando o endereço de sua página no Facebook e registrando as atividades de todas as postagens e compartilhamentos realizados no período de 01 de janeiro a 30 de junho de 2016. Após a coleta as postagens foram agrupadas por categoria conforme descrição do Quadro 2, em seguida com o objetivo de avaliar o desempenho da página da biblioteca foram aferidas as métricas de audiência, engajamento, influência e conversão próprias do marketing digital (MACEDO, 2014).

Quadro 2 - Categorias das postagens

\begin{tabular}{|l|l|}
\hline $\begin{array}{l}\text { Categorias das } \\
\text { postagens }\end{array}$ & \multicolumn{1}{c|}{ Descrição } \\
\hline Serviços oferecidos & $\begin{array}{l}\text { Postagens referentes as atividades realizadas habitualmente pela } \\
\text { instituição: exibição de filmes; Biblio tour; hora do conto. }\end{array}$ \\
\hline \multirow{3}{*}{ Eventos } & $\begin{array}{l}\text { A) Eventos que acontecem dentro da biblioteca de forma esporádica: } \\
\text { encontros, bate papo; cursos; exposições; palestras; lançamentos de } \\
\text { livros; recitais de poesias. }\end{array}$ \\
\cline { 2 - 3 } Bvisos & $\begin{array}{l}\text { Informações sobre horário de funcionamento; cronograma mensal de } \\
\text { atividades; novas aquisições. }\end{array}$ \\
\hline Biblioteca na mídia & $\begin{array}{l}\text { Notícias que façam menções sobre a biblioteca em matérias: em sites, } \\
\text { televisão ou em qualquer outro meio de comunicação. }\end{array}$ \\
\hline Outras & $\begin{array}{l}\text { Postagens que não se enquadram em nenhuma das outras categorias } \\
\text { acima. }\end{array}$ \\
\hline
\end{tabular}

Fonte: Adaptado de Calil Junior e Almendra (2016).

\section{ANÁLISE E DISCUSSÃO DOS RESULTADOS}

Os resultados são apresentados em 3 agrupamentos de dados. No primeiro discorreremos sobre o quantitativo dos dados coletados na página (curtidas e postagens), no segundo apresentaremos a análise da categorização das postagens e por fim, discorreremos sobre o desempenho das métricas. Até o último dia do período da análise, a página da BPEGR possuía 1728 likes, ou seja, 1728 curtidas. 0 conteúdo e atuação da página expresso nas postagens e compartilhamentos são realizadas pela atual coordenadora, que é bibliotecária.

Após a coleta de dados realizada na página do Facebook da BPEGR foram contabilizadas todas as postagens, por mês e separadas por pastas em ordem cronológicas referente aos meses da análise, o que resultou um total de 73 postagens, distribuídas na 
Tabela 1. Das quais 33 postagens são fruto de compartilhamentos de outros perfis sendo que 23 dessas postagens são do perfil da SECULT órgão responsável pela biblioteca enquanto equipamento cultural do Estado.

Tabela 1 - Postagens por mês.

\begin{tabular}{|c|c|c|}
\hline Mês & Postagem & $\mathbf{( \% )}$ \\
\hline Janeiro & 10 & 7,3 \\
\hline Fevereiro & 15 & 11,0 \\
\hline Março & 13 & 9,5 \\
\hline Abril & 13 & 9,5 \\
\hline Maio & 14 & 10,2 \\
\hline Junho & 8 & 5,8 \\
\hline Total & $\mathbf{7 3}$ & $\mathbf{1 0 0}$ \\
\hline
\end{tabular}

Fonte: Dados da pesquisa, 2016.

Tendo como base as métricas de audiência citadas Macedo (2014) como as que evidenciam à exposição de conteúdo, números de curtidas da fan page, e a frequência de publicações que a página possui, percebemos que a BPEGR tem no período 73 postagens, com uma média de 12 postagens/mês e que os únicos meses abaixo dessa média foram os meses de janeiro e o de junho. No entanto, se comparado ao estudo de Calil Junior e Almendra (2016) o valor total de postagens por um período também de seis meses é bem inferior aos das bibliotecas públicas dos estados do Acre (366 postagens), Paraná (280 postagens) e São Paulo (618 postagens), superando apenas o estado do Pernambuco (57 postagens). As publicações também foram analisadas quanto ao contexto e propósito do seu conteúdo dentro das categorias consideradas no estudo, conforme Gráfico 1.

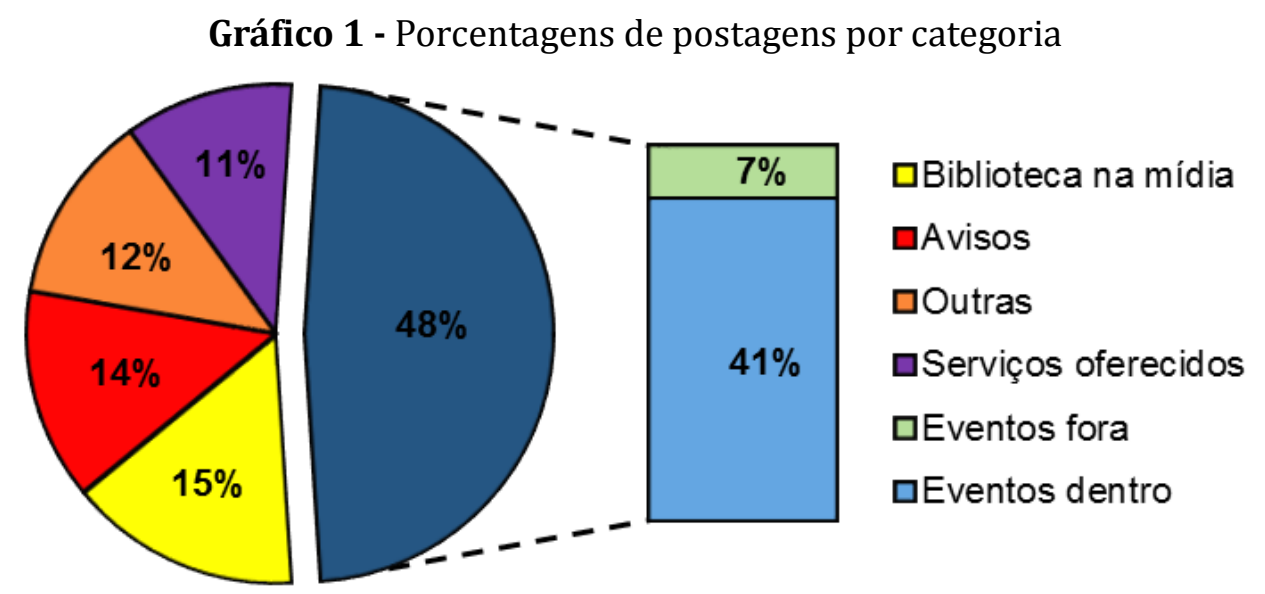

Fonte: Dados da pesquisa, 2016. 
A promoção de unidades de informação como estratégia de marketing, ao divulgar a diversidade que a biblioteca pública oferece aos cidadãos no âmbito de suas funções educacional, cultural, social, recreativa, política e informativa, pode conferir maior visibilidade para instituição (AMARAL, 1990). Na sua atuação no Facebook, a maioria das publicações da BPEGR foi sobre "Eventos" com um total de 35 postagens (48\%). Desse total a divulgação de eventos que acontecem dentro da biblioteca encontros, bate papo e exposições é mais frequente do que os eventos organizados pela instituição que acontecem fora dela. A categoria "Biblioteca na mídia" foi a segunda mais significativa $(\mathrm{n}=11 ; 15 \%)$, seguida por "Avisos" ( $\mathrm{n}=10 ; 14 \%)$ e "Outros" ( $\mathrm{n}=9 ; 12 \%)$. Por último, a categoria "Serviços oferecidos" foi a que apresentou o menor número de postagens com apenas 8 publicações (11\%).

0 resultado é similar ao encontrado no estudo de Calil Junior e Almendra (2016), sobretudo para as bibliotecas públicas dos estados do Paraná, Pernambuco e São Paulo, nas quais postagens sobre eventos superam as informativas que versam sobre produtos e serviços das bibliotecas. Consideramos como positivo inclusive o fato da categoria "Eventos dentro" ter mais postagens e que tal recorrência reflete o quanto a biblioteca se preocupa em manter os usuários informados quanto aos eventos que acontecem dentro da instituição, tornando-a mais atrativa.

A pesquisa procurou também analisar o quanto o conteúdo postado mobilizou os usuários. Assim foi feito um levantamento em todas as categorias quanto ao indicativo de interação nas postagens nas ações de "curtir", "comentar" e "compartilhar" que podem ser observados no Gráfico 2. Tais funcionalidades revelam-se como termômetros do engajamento e influência, pois servem como indicadores de valores na avaliação do alcance do público em relação ao conteúdo publicado e sua relevância. 
Gráfico 2 - Índice de engajamento geral

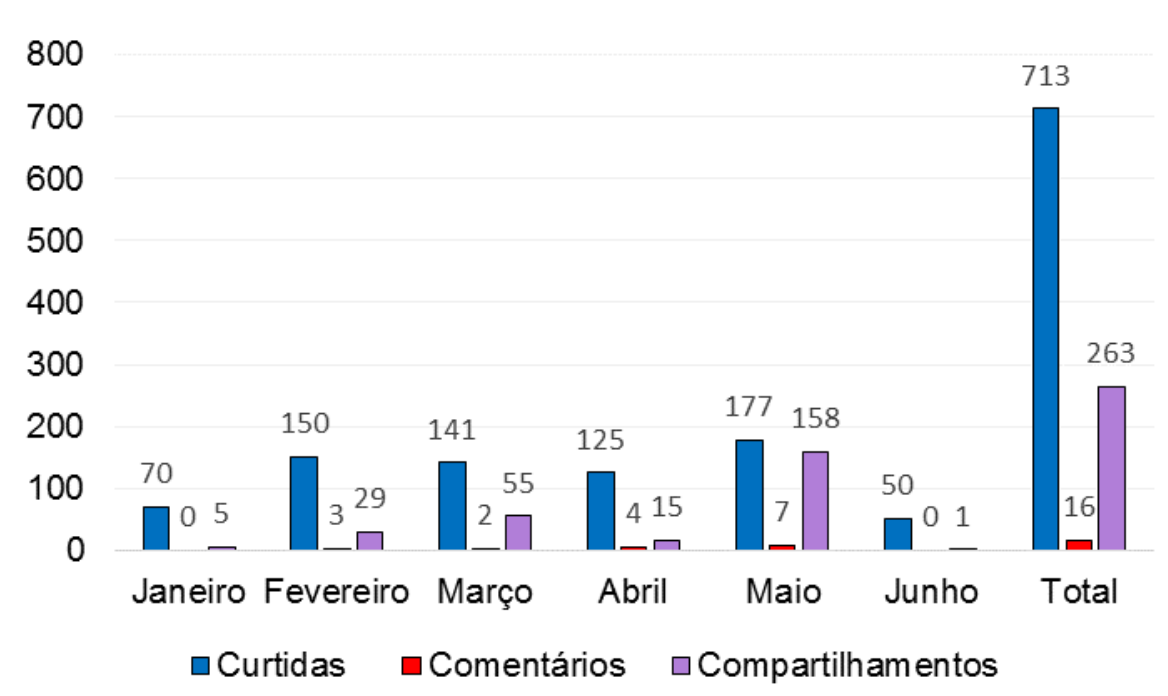

Fonte: Dados da pesquisa, 2016.

A ação de "curtir" foi a mais expressiva das interações, no total somaram 713, atingindo mais de 100 curtidas mensais em quanto dos seis meses, seguido da ação de "compartilhar", funcionalidade com 263 registros. E o com menor desempenho de interação por parte dos usuários a ação de "comentar" só foi utilizada 16 vezes. Esse tipo de resultado com valores superiores para ações de curtir, diminuindo o desempenho de compartilhar e sendo mais tímido ainda o número de comentários parece ser condizente com estudos que medem o grau de interação e engajamento de usuários com conteúdos nas mídias sociais, isso porque, essas ações são distintas e exigem uma carga de comprometimento com o conteúdo diferenciado.

A ação de "curtir" pode ser considerada uma forma de apoio e concordância, funcionando como uma espécie de legitimação do conteúdo e demanda menor esforço do usuário, ao passo que o "compartilhar" tem a função "dar visibilidade para a conversação ou da mensagem, ampliando o alcance dela, valorizando informação que foi originalmente publicada", os “comentários", por sua vez, são percebidos como práticas mais evidentes do diálogo que trazem uma efetiva contribuição para a conversação, "demandando um maior esforço e acontecendo quando os usuários têm algo a dizer sobre o assunto" (RECUERO, 2014, p.120).

Ainda que possuam propósitos distintos, os valores de cada uma dessas ações releva que os usuários não estão alheios aos conteúdos postados pela BPEGR e confirmam o quanto uso das mídias sociais pode ser relevante tanto para a biblioteca, quanto para a comunidade atendida e o grande público, pois por meio desse dispositivo informacional a 
biblioteca consegue disseminar as mais diversas informações que envolvem a instituição, possibilitando possivelmente atrair mais usuários potenciais e informar os usuários reais. Para exemplificar algumas dessas interações selecionamos algumas postagens e as descrevemos a seguir. A postagem da Figura 1 relata uma homenagem da Secretaria de Estado da Cultura, às mulheres escritoras alagoanas em alusão ao dia internacional da mulher, e convida toda sociedade a prestigiar.

Figura 1 - Postagem de um evento da biblioteca

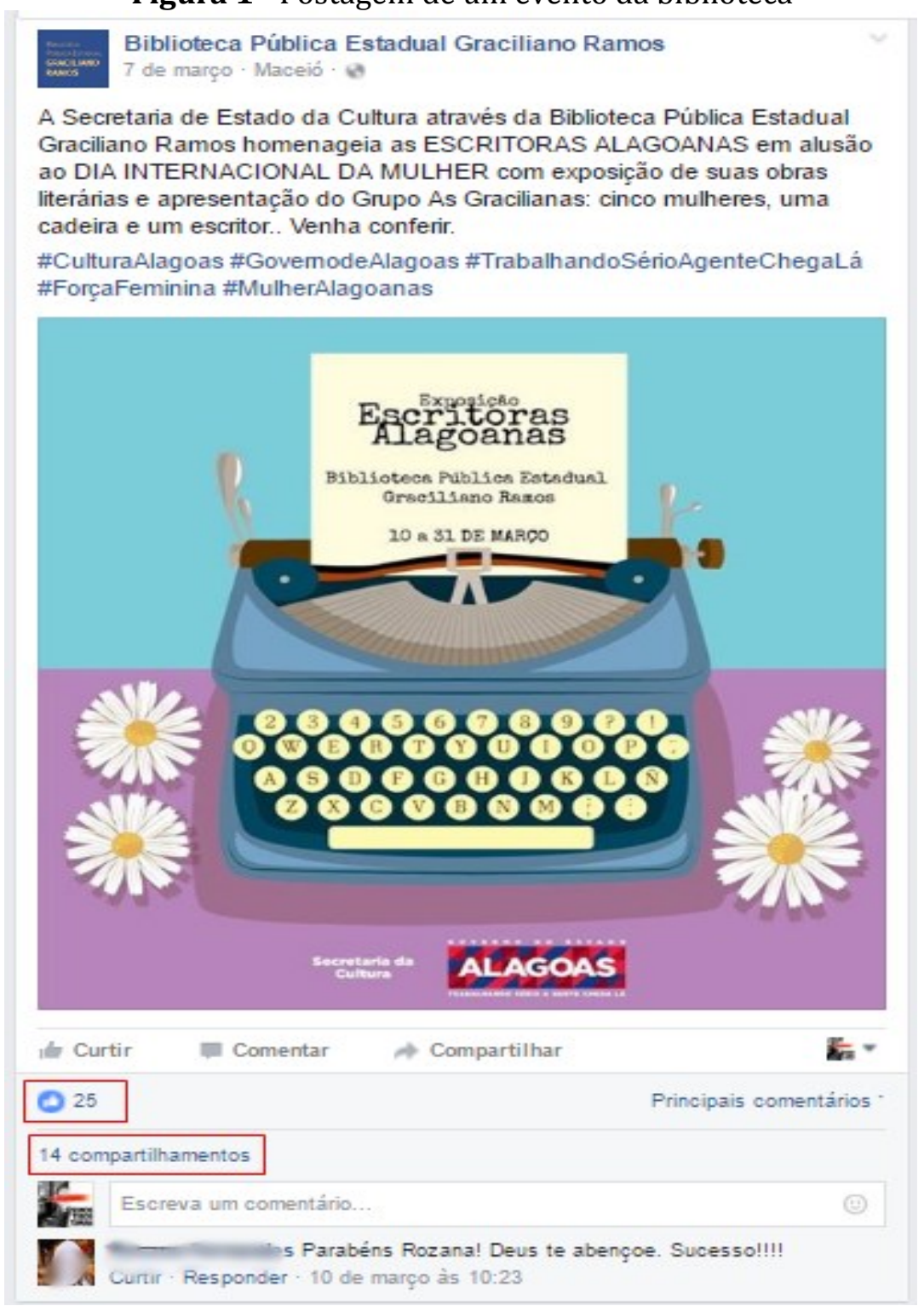

Fonte: Fanpage Biblioteca, 2016.

A postagem obteve um engajamento de 25 curtidas e 14 compartilhamentos e um comentário no qual uma seguidora da página parabeniza e deseja sucesso à outra usuária, o que reflete o indicador de reputação citado do Recuero (2009) quando retrata sobre a 
percepção do outro em relação a alguém na rede. A segunda postagem (Figura 2) obteve o maior número de compartilhamentos (15). Trata-se de uma publicação sobre uma matéria de um portal de notícia que está divulgando um evento de troca de livros dentro da biblioteca, essa publicação conseguiu alcançar uma boa interação por parte dos usuários, além dos compartilhamentos, obteve 29 curtidas e 2 comentários.

Figura 2 - Postagem de uma matéria sobre um evento da biblioteca

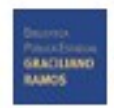

Biblioteca Pública Estadual Graciliano Ramos

1 de fevereiro - 0

TROCA DE LIVROS É NA BIBLIOTECA PÚBLICA ESTADULA GRACILIANO RAMOS. Venha trocar o seu!!!

http://g1.globo.com/.../troca-de-livros-e-opcao-econ.../4769098/

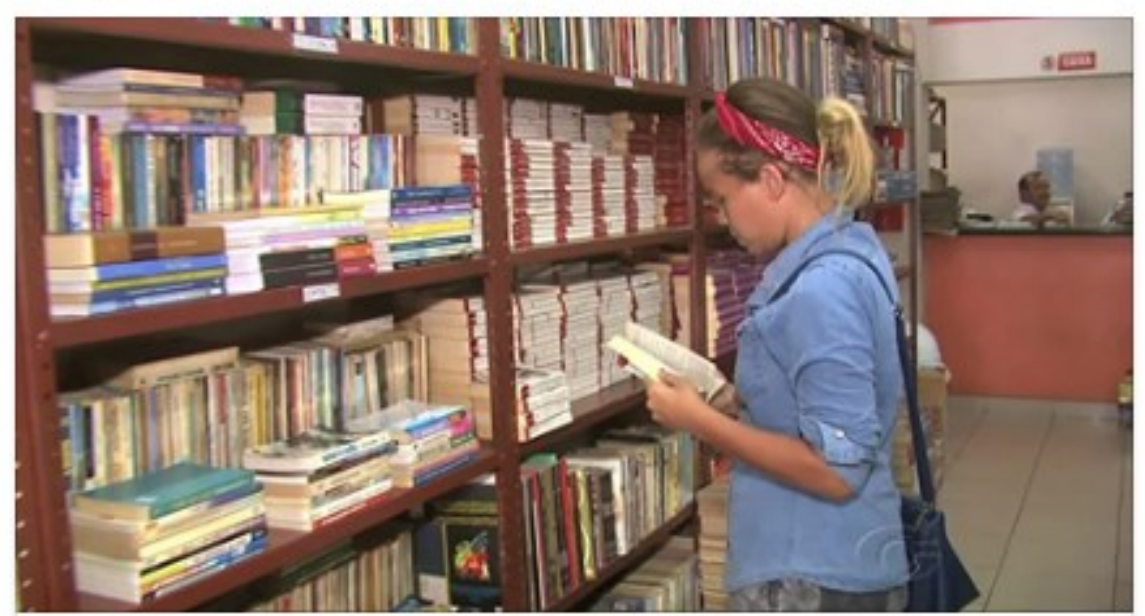

Troca de livros é opção econômica para leitores - G1 Alagoas - Bom Dia Alagoas - Catálogo de Vídeos

Biblioteca pública recebe livros de doação para prestar serviço de troca de livros.

G1.GLOBO.COM

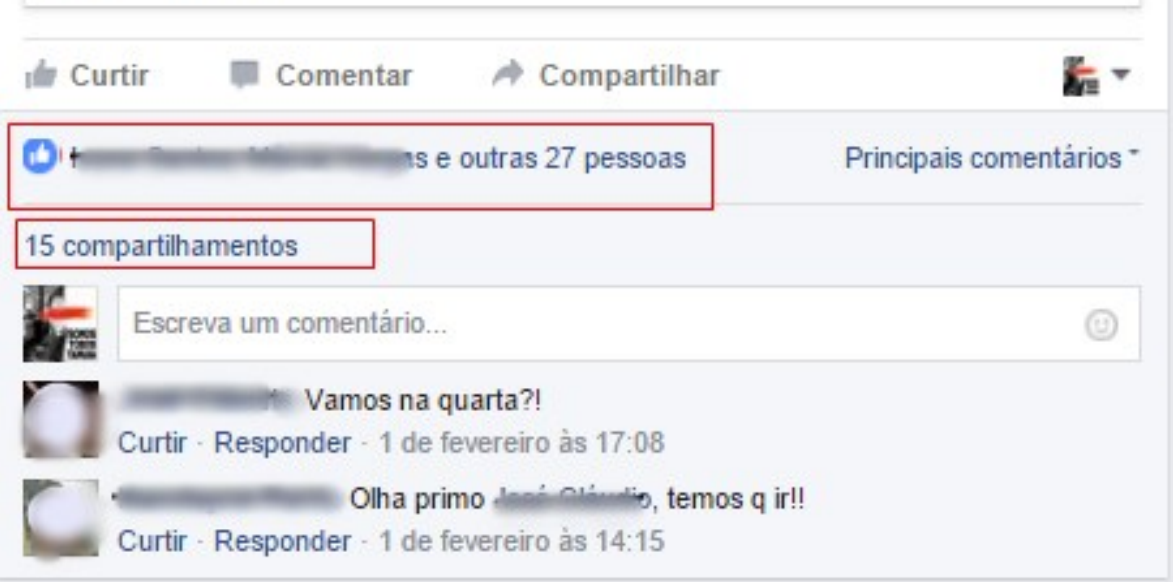

Fonte: Fanpage Biblioteca, 2016. 
$\mathrm{Na}$ conversação estabelecida entre os usuários nos comentários percebemos inclusive o diálogo entre dois seguidores dos quais um convida outro e combina de irem até a biblioteca participar do evento de troca de livros. Entretanto, não houve nenhuma interação por parte do perfil da BPEGR nos comentários dos usuários, o que seria interessante para estreitar os laços e acarretar uma movimentação a mais na publicação, que consequentemente poderia ocasionar uma maior visibilidade da postagem dentro da mídia social perante os usuários.

Outra postagem que obteve movimentação dos indicadores de valores utilizados para perceber engajamento do público pode ser vista na Figura 3 sobre o evento "Conversando sobre Saúde" com divulgação de palestra sobre AIDS ocorrido no mês de maio.

Figura 3 - Postagem do evento "Conversando sobre Saúde"

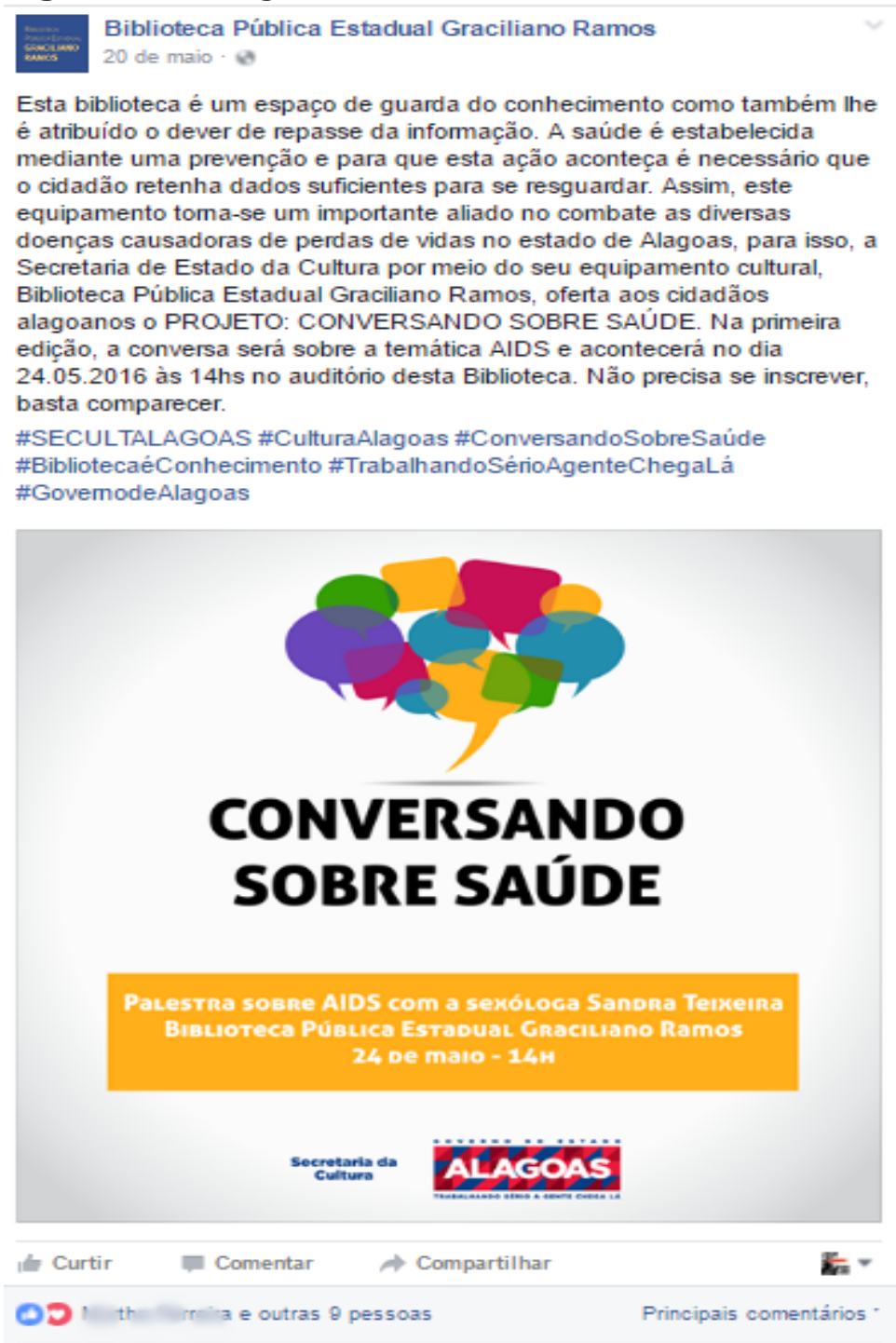

Fonte: Fanpage Biblioteca, 2016. 
A publicação ressalta o papel da biblioteca enquanto "espaço de guarda de conhecimento e seu dever no repasse da informação" assim como também se apresenta em forma de um convite para população comparecer ao evento "Conversando Sobre Saúde", o que vai de encontro com o Manifesto da IFLA/UNESCO (1994) ao determinar algumas missões relacionadas com ao acesso à informação, a alfabetização, a educação e a cultura serem seguidas pela rede de Bibliotecas Públicas. A Figura 4 ilustra o engajamento que a publicação gerou (10 curtidas e 52 compartilhamentos).

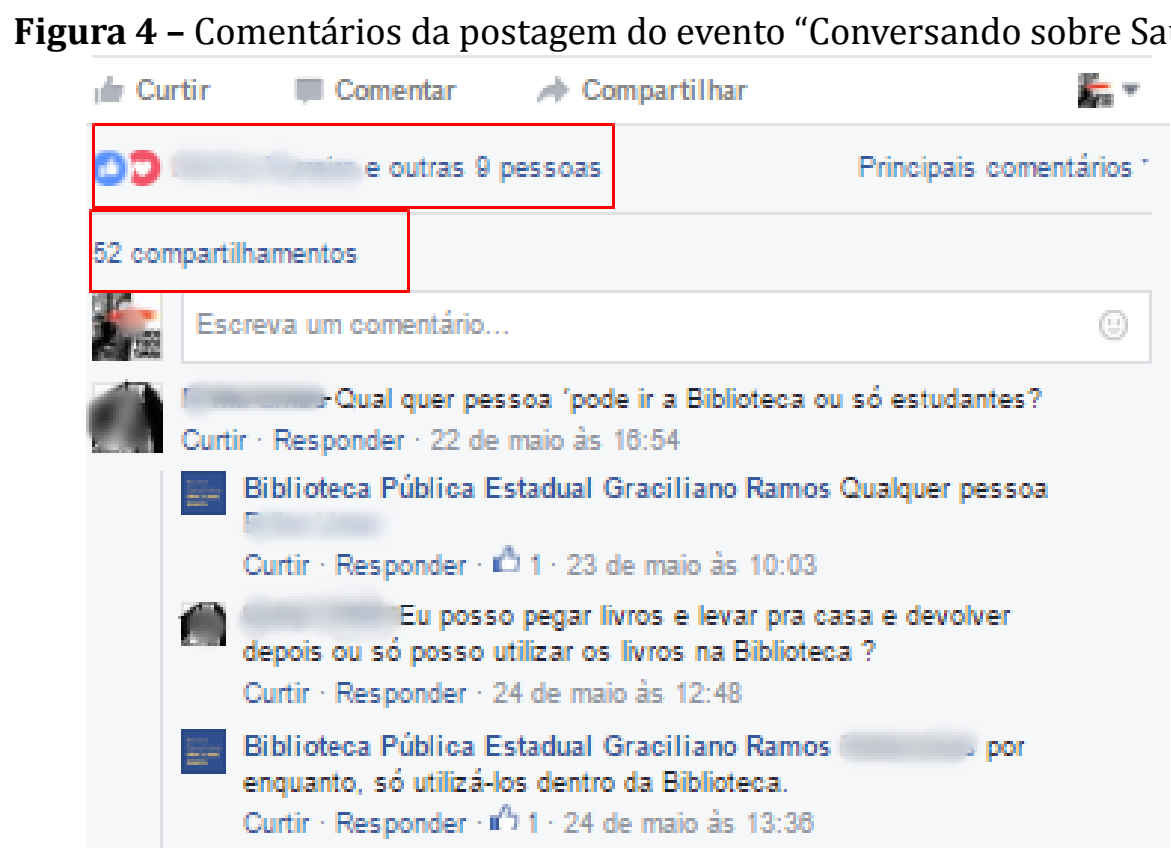

Fonte: Fanpage Biblioteca, 2016.

A conversação estabelecida nos "comentários" expressa esse dispositivo na mediação da informação entre a biblioteca e os seguidores da página, inclusive como canal para os usuários tirarem dúvidas como quem pode frequentar a biblioteca e sobre a utilização do acervo. Inclusive podemos perceber nessa conversação a participação do perfil da biblioteca respondendo aos usuários.

A partir da movimentação das funcionalidades de interação utilizadas para mensurar as métricas de engajamento na mídia social Facebook foi possível perceber a métrica de influência (MACEDO, 2014) a partir do comportamento dos usuários ao compartilharem uma publicação da página da BPEGR. A métrica de influência relacionase com o grau de autoridade (RECUERO, 2009), está diretamente ligado à capacidade que os conteúdos da BPEGR possuem de mobilizar um número significativo de usuários, levando-os a compartilhar (Figura 5) o conteúdo publicado na página da biblioteca. 
Figura 5 - Sequência dos compartilhamentos da postagem do evento "Conversando sobre Saúde"

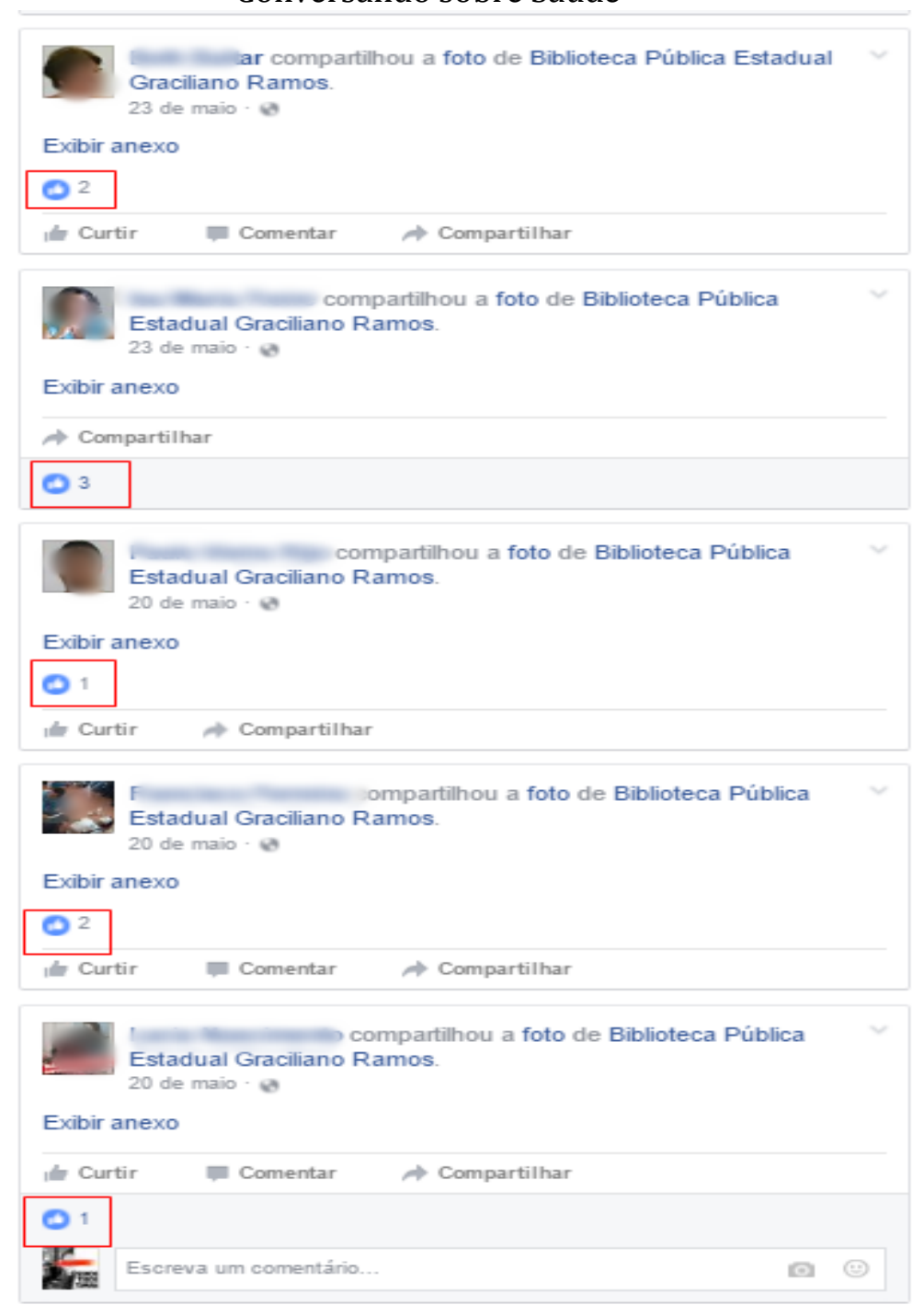

Fonte: Fanpage Biblioteca, 2016.

A partir das interações expressas na sequência desses compartilhamentos da postagem da BPGR é possível observar os perfis dos usuários, sendo: uma bibliotecária, duas professoras e dois estudantes de graduação de diferentes cursos, o que nos remete a característica do público diversificado que a biblioteca deve atender (SUAIDEN, 1995). Inclusive nos faz perceber como indicador de autoridade (RECUERO, 2009) ou melhor o poder de influência que a biblioteca tem perante as suas conexões na rede, ou seja, os seus usuários e como eles podem ser influenciados pela biblioteca ao compartilhar e se tornarem influenciadores de outros usuários.

A ausência de metas claras para serem alcanças no conjunto de publicações da BPEGR impossibilitou a verificação da métrica de conversão, já que esse indicador se baseia nos quantitativos das metas, ou seja, nos resultados alcançados, o que poderia 
incluir o quantitativo de público determinada uma ação ou evento divulgado na mídia social (MACEDO, 2014). Por esse motivo não foi possível mapear separadamente o número de usuários alcançados perante as atividades ou eventos divulgados na mídia social. No entanto, para ao menos aproximarmos desse aspecto da pesquisa, optou por se fazer uma comparação entre o número de postagens e o outro possível dado de conversão, o número de visitantes que a biblioteca recebeu no mesmo período (Gráfico 3).

Gráfico 3- Número de usuários que visitaram a biblioteca por mês

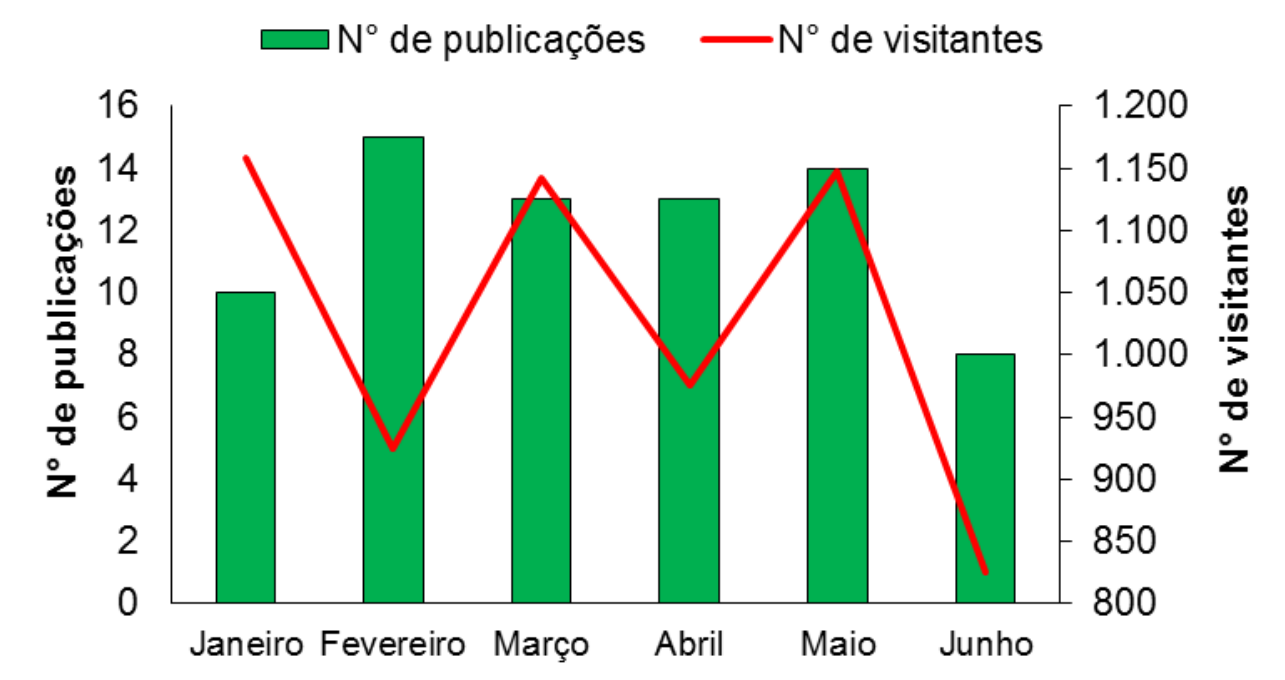

Fonte: Dados da pesquisa, 2016.

Levando em consideração a quantidade de visitantes e o índice mensal de postagens da página da BPEGR percebemos que o mês janeiro contou com 10 publicações e obteve 1158, o maior número de visitantes no período. Já o mês de fevereiro, embora tenha o maior número de postagens (15), não manteve o índice de visitantes do mês anterior, caracterizando como o segundo mês que obteve o menor número de visitas. Nos meses de março, abril e maio houve variação quanto ao número de visitantes à biblioteca, no entanto a página da BPEGR manteve o número de postagens sem muita variação, por outro lado o mês de junho obteve o menor índice 8 publicações, consequentemente foi o mês que alcançou o menor números de visitantes. Assim, os dados não nos permitem aferir alguma relação entre a frequência de postagens e o número de visitas, embora possa futuramente ser utilizado pela biblioteca como variável para verificação da métrica de conversão, desde que se estabeleça como meta, por exemplo, o aumento de visitas em n\%. 


\section{CONSIDERAÇõES FINAIS}

No presente estudo buscou-se evidenciar o uso das mídias sociais como estratégia de marketing nas unidades de informação, a partir de um estudo de caso com análise de dados da página da Biblioteca Pública Estadual Graciliano Ramos no Facebook. No âmbito do marketing digital, enfatizou-se o uso das mídias sociais como estratégia de marketing como sendo um dos caminhos para se trabalhar a imagem da biblioteca e atuar atenta aos novos contextos e dispositivos de informação em ambientes digitais, cada vez mais povoado pelos usuários.

Podemos perceber como o uso das mídias sociais é relevante para a disseminação e compartilhamento de informações e promoção dos produtos e serviços da biblioteca e ampliação de sua rede de relações a um número maior de pessoas, fazendo com que a informação circule de forma mais rápida, o que torna um ambiente bastante atrativo para desenvolver as mais diversificadas ações de marketing. Uma vez que, o público-alvo (usuário/ cliente) também participa como produtor de conteúdo, o que pode ocasionar uma relação de maior proximidade entre o usuário e a biblioteca.

A análise dos dados da pesquisa nos indica, a partir do desempenho das métricas de audiência, engajamento e influência, que a Biblioteca Pública Estadual Graciliano Ramos ainda não utiliza a potencialidade da mídia social por completo. A biblioteca utiliza sua página basicamente como mecanismo de divulgação dos eventos, produtos e serviços oferecidos pela instituição, o que é importante, mas não se enquadra como uma estratégia de marketing se ela não estabelece metas para serem alcançadas, o que inclusive comprometeu verificar a métrica de conversão, e atua de forma pouco responsiva participando timidamente das conversações geradas por suas postagens.

Diante disso a instituição precisa estar atenta em sempre buscar inovar em estratégias, a fim de engajar mais o público consequentemente atingir uma maior visibilidade para instituição. Em vista disso listamos algumas sugestões para a Biblioteca Pública Estadual Graciliano Ramos: 1) Criação de um plano de marketing digital em conjunto com o planejamento estratégico de atividades realizadas pela biblioteca, estabelecendo metas e formas de avaliação; 2) Adesão a outras mídias sociais; 3) Planejamento e gestão de conteúdo com indicação de tipos de postagens, frequência de publicação e equilíbrio entre conteúdos próprios e de terceiros; 4) Atuação atrativa e responsiva. 


\section{REFERÊNCIAS}

AMARAL, Sueli Angelica do. Marketing e gerencia de biblioteca. Revista de Biblioteconomia de Brasília, Brasília, v.18 n.2 p.311-317, jul./dez. 1990. Disponível em:<

http://basessibi.c3sl.ufpr.br/brapci/index.php/article/download/17716>. Acesso em: 16 jun. 2016.

Marketing: abordagem em unidades de informação. Brasília: Thesaurus, 1998.

. Marketing no ciberespaço: o desafio profissional das unidades de informação brasileiras no contexto da sociedade da informação. Revista de Biblioteconomia de Brasília, Brasília v. 23/24, n 1, p. 68-88, 1999,2000. Disponível em:

<http://revista.ibict.br/ciinf/article/download/631/635.> Acesso em: 20 fev. 2016.

Marketing na ciência da informação. Brasília: Editora Universidade de Brasília, 2007.

. Marketing da Informação: entre a promoção e a comunicação integrada de marketing.

Informação\& Sociedade, Estudos, João Pessoa, v.18, n.1, p.31-44, jan./abr. 2008. Disponível em: <http://www.ies.ufpb.br/ojs/index.php/ies/article/view/1636/1637>. Acesso em: 22 maio 2016.

ARAÚJO, Ronaldo Ferreira de. Marketing científico digital e métricas alternativas para periódicos: da visibilidade ao engajamento. Perspect. ciênc. inf., Belo Horizonte v.20, n.3, p.67-84, jul./set. 2015. Disponível em: <http://dx.doi.org/10.1590/1981-5344/2402>. Acesso em: 22 jun. 2016.

ARRUDA, Maria Izabel Moreira. Desafios da biblioteca pública na era da informação: estudo comparativo realizado no Porto, Portugal, e em Belém, Brasil. Tese (Doutorado). Faculdade de Letras, Universidade do Porto, Porto, 2013, 301 p.

BLATTMANN, Ursula; CORRÊA DA SILVA, Fabiano Couto. Colaboração e interação na Web 2.0 e Biblioteca 2.0. Revista ACB: Biblioteconomia em Santa Catarina, Florianópolis, v.12, n.2, p.191215, jul./dez., 2007. Disponível em: <https://revista.acbsc.org.br/racb/article/view/530>. Acesso em 18 jun. 2016.

CALIL JUNIOR, Alberto; ALMENDRA, Gabriela. As apropriações do Facebook pelas bibliotecas públicas estaduais brasileiras. Em Questão, Porto Alegre v.22, n.1, p.188-213, jan/abr. 2016. Disponível em:<http://seer.ufrgs.br/index.php/EmQuestao/article/view/54826/35431>. Acesso em: 12 fev. 2016.

GABRIEL, Martha. Marketing na Era digital. São Paulo: Novatec Editora, 2010.

IFLA/UNESCO. Manifesto da IFLA/UNESCO sobre bibliotecas públicas. 1994.Disponível em: $<$ http://archive.ifl.org/VII/S8/unesco/port.htm>. Acesso em: 14 jul. 2016.

KOTLER, Philip. Marketing para organizações que não visam o lucro. São Paulo: Atlas, 1978.

MACEDO, T. Métricas de marketing digital sua aplicação nas ações de marketing das organizações: estudo de caso múltiplos. 2014. 119f. Dissertação (Mestrado em Administração) Universidade federal do Rio grande do Sul, Escola de Administração, Programa de Pós-Graduação em Administração, Porto Alegre, 2014. 
OTTONI, Heloisa Maria. Bases do marketing para unidades de informação. Ciência da Informação, Brasília, v.25, n.2, 1995. Disponível em: <http://

www.ibict.br/cionline/250296/250203.pdf>. Acesso em: 12 jul. 2016.

PRADO, Jorge Moisés Kroll do; CORREA, Elisa Cristina Delfini. Bibliotecas universitárias e presença digital: estabelecimento de diretrizes para o uso de mídias sociais. Perspect. ciênc. inf., Belo Horizonte , v. 21, n. 3, p. 165-181, set. 2016. Disponível em: <http://dx.doi.org/10.1590/1981-5344/2733>. Acesso em: 15 dez, 2017.

RECUERO, Raquel. Redes sociais na internet. Porto Alegre: Sulina, 2009.

. Curtir, compartilhar, comentar: trabalho de face, conversação e redes sociais no Facebook. Verso e Reverso, v.28, n.68, p.114-124, mai. Ago., 2014. Disponível em: < http://www.revistas.unisinos.br/index.php/versoereverso/article/viewFile/7323/4187>. Acesso em: 25 jul. 2016.

SANT'ANA, Moacir Medeiros. Pequena história da Biblioteca Pública Estadual. Maceió: Governo do Estado de Alagoas, Impressa Oficial Graciliano Ramos 2014.

SANTOS, Almiraci Dantas dos. (Coord.) Relatório Anual de Atividade da Biblioteca Pública Estadual Graciliano Ramos, Maceió: Secretaria de Estado da Cultura, 2015.

SANTOS, Almiraci Dantas dos. (Coord.) Relatório semestral de visitas dos usuários à Biblioteca Pública Estadual Graciliano Ramos, Maceió: Biblioteca Pública Estadual Graciliano Ramos, 2016.

SUAIDEN, Emir José. Biblioteca pública e informação à comunidade. São Paulo: Global, 1995.

Recebido em: 29 de agosto de 2017 Aceito em: 22 de novembro de 2017 